\title{
Aldosterone promotes renal interstitial fibrosis via the AIF-1/AKT/mTOR signaling pathway
}

\author{
XUEYING YUAN, XINGZHI WANG, YUSHU LI, XIN LI, SHUYU ZHANG and LIRONG HAO \\ Department of Nephropathy and Hemodialysis, The First Affiliated Hospital of \\ Harbin Medical University, Harbin, Heilongjiang 150001, P.R. China
}

Received February 7, 2019; Accepted July 5, 2019

DOI: $10.3892 / \mathrm{mmr} .2019 .10680$

\begin{abstract}
A number of studies have shown that aldosterone serves an important role in promoting renal interstitial fibrosis, although the specific mechanism remains to be elucidated. A previous study revealed that the fibrotic effect of aldosterone was associated with the expression of allograft inflammatory factor 1 (AIF-1) in RAW264.7 macrophage cells, in a timeand concentration-dependent manner. However, the exact mechanism through which aldosterone promotes renal interstitial fibrosis remains unknown. In the present study, the effects of aldosterone on renal inflammatory cell infiltration, collagen deposition and the expression levels of AIF-1, phosphatidylinositol 3-kinase (PI3K), AKT serine/threonine kinase (AKT), mammalian target of rapamycin (mTOR), the oxidative stress factor NADPH oxidase 2 (NOX2) and nuclear transcription factor erythroid-related factor 2 (Nrf2) were assessed in normal rats, rats treated with aldosterone, rats treated with aldosterone and spironolactone and those treated with spironolactone only (used as the control). The effect of aldosterone on these factors was also investigated in the renal interstitium of unilateral ureteral obstruction (UUO) rats. Additionally, the AIF-1 gene was overexpressed and knocked down in macrophage RAW264.7 cells, and the effects of aldosterone on PI3K, AKT, mTOR, NOX2 and Nrf2 were subsequently investigated. The results showed that aldosterone promoted inflammatory cell infiltration, collagen deposition and the expression of AIF-1, PI3K, AKT, mTOR and NOX2, but inhibited the expression of Nrf2. In the UUO rats, aldosterone also promoted renal interstitial inflammatory cell infiltration, collagen deposition and the expression of AIF-1, NOX2, PI3K, AKT and mTOR, whereas the expression
\end{abstract}

Correspondence to: Dr Lirong Hao, Department of Nephropathy and Hemodialysis, The First Affiliated Hospital of Harbin Medical University, 23 Youzheng Street, Nangang, Harbin, Heilongjiang 150001, P.R. China

E-mail: hao__lirong@163.com

Key words: aldosterone, fibrosis, allograft inflammatory factor 1, serine/threonine kinase/mammalian target of rapamycin, oxidative stress of Nrf2 was downregulated by aldosterone compared with that in the UUO-only group; the influence of aldosterone was counteracted by spironolactone in the normal and UUO rats. In vitro, aldosterone upregulated the expression levels of AKT, mTOR, NOX2 and Nrf2 in RAW264.7 cells compared with those in untreated cells. Suppressing the expression of AIF-1 inhibited the effects of aldosterone, whereas the overexpression of AIF-1 enhanced these effects in RAW264.7 cells. These findings indicated that aldosterone promoted renal interstitial fibrosis by upregulating the expression of AIF-1 and that the specific mechanism may involve AKT/mTOR and oxidative stress signaling.

\section{Introduction}

Fibrosis is defined by the excessive deposition of collagenous and non-collagenous extracellular matrix components in organs and tissues. Previous studies have demonstrated the importance of aldosterone in the inflammatory and fibrotic processes of kidney diseases, in which the profibrotic effects of aldosterone are a consequence of both aldosterone-induced hypertension and its effect on inflammatory cells and myofibroblasts $(1,2)$. The promotion of renal lesions caused by aldosterone is commonly accompanied by a considerable inflammatory response, primarily involving the release of inflammatory factors by macrophages during renal fibrosis.

Allograft inflammatory factor 1 (AIF-1) serves an important role in aldosterone-induced renal fibrosis (3) and is secreted by macrophages, fibroblasts, endothelial cells and smooth muscle cells in a number of immune-inflammatory disorders $(4,5)$. As a modulator of the immune response, AIF-1 promotes the proliferation and migration of macrophages and human vascular smooth muscle cells (6). It also promotes the expression of inflammatory mediators, including cytokines and chemokines, in macrophages, which in turn inhibits macrophage apoptosis (7). Previous findings have indicated that the expression of AIF-1 is a key component in the pathogenesis of systemic sclerosis (SSc). Elevated expression of AIF-1 was found in SSc-affected tissues and peripheral blood mononuclear cells (8), which suggests that AIF-1 may serve an important role in renal interstitial fibrosis. Therefore, the present study aimed to investigate the role of AIF-1 in aldosterone-induced renal interstitial fibrosis. 
AIF-1 has been found to protect fibroblast-like synoviocytes from NO-induced apoptosis by promoting the phosphorylation of AKT serine/threonine kinase (AKT), and this effect was subsequently inhibited by pretreatment with a phosphatidylinositol 3-kinase (PI3K) inhibitor (9). The knockdown of AIF-1 in macrophages significantly reduced the expression of phosphorylated (p-)AKT (10), suggesting a close association between the expression of AIF-1 and signaling transduction within the PI3K/AKT/mammalian target of rapamycin (mTOR) pathway. mTOR is a protein kinase regulated by a large number of signaling molecules, including PI3K and AKT. It has been highlighted as an important regulator of renal diseases, including diabetic nephropathy (11) and acute kidney injury (12); the phosphorylation of constituents of the PI3K/AKT/mTOR pathway was significantly increased in the kidneys of unilateral ureteral obstruction (UUO) rats (13). Additionally, aldosterone can bind with cytoplasmic mineralocorticoid receptors in kidney fibroblasts, resulting in the transactivation of growth factor receptors. This has been shown to facilitate the rapid activation of PI3K and AKT, whereas the inhibition of PI3K prevented this aldosterone-induced proliferative response (14). Therefore, it was hypothesized that the effect of AIF-1 in aldosterone-induced renal interstitial fibrosis was considered to be associated with activation of the PI3K/AKT/mTOR signaling pathway.

Aldosterone-induced renal interstitial fibrosis is also associated with oxidative stress (15). NADPH oxidase 2 (NOX2), an important member of the NADPH oxidases (NOXs), is expressed at high levels in kidney tubular cells (16) and serves a principal role in renal ischemia-reperfusion injury (17) and fibrosis (18). Nuclear transcription factor erythroid-related factor 2 (Nrf2) regulates antioxidative and anti-inflammatory reactions during tissue injury. Previous studies have illustrated that silencing of the Nrf2 gene intensified inflammation, oxidative stress and histological changes. In a rat model of chronic interstitial nephritis, the activation of Nrf2 was significantly reduced and expression of its target genes was downregulated (19). The overexpression of angiotensinogen in renal proximal tubular cells resulted in the cytosolic accumulation of $\mathrm{Nrf} 2$ and reduced the translocation of Nrf2 into the nucleus, subsequently limiting the expression of antioxidant-associated genes (20).

Therefore, aldosterone-induced renal injury is associated with the upregulation of AIF-1, although it is not clear whether AIF-1 functions through the PI3K/AKT/mTOR signaling pathway. Furthermore, NOX2 and Nrf2 are involved in oxidative stress during renal injury, but how this is affected by AIF-1 under the influence of aldosterone remains to be fully clarified. The present study aimed to elucidate the underlying molecular mechanisms of aldosterone-induced renal fibrosis and to determine the specific effects of AIF-1 on PI3K/AKT/mTOR signaling, NOX2 and Nrf2 in this pathogenic process.

\section{Materials and methods}

Animals. Male Wistar rats (6-8 weeks of age, 200-250 g) were purchased from the Experimental Animal Center of the Second Affiliated Hospital of Harbin Medical University, (Harbin, China). Animal experiments were performed in accordance with the Guiding Principles for the Care and Use of Laboratory Animals (updated 2011; National Institutes of
Health, Bethesda) and were approved by the Experimental Animal Usage and Welfare Ethics Committee of Harbin Medical University. Upon arrival, the animals were allowed an adjustment period of 1 week and were housed in standard cages in a quiet room on a 12-h light-dark cycle. The facility was maintained at $20-22^{\circ} \mathrm{C}$ with a humidity of $50-60 \%$. All rats were fed with standard pellet laboratory chow and allowed free access to water.

The animals were randomly divided into seven groups ( $n=10$ in each group) as follows: i) Control (sham-surgery and distilled water infusion as vehicle); ii) aldosterone; iii) aldosterone + spironolactone; iv) spironolactone; v) UUO; vi) UUO + aldosterone; and vii) UUO + aldosterone + spironolactone. Aldosterone (Sigma-Aldrich; Merck KGaA) was administered using an osmotic pump $(0.75 \mu \mathrm{g} / \mathrm{h}$, subcutaneous infusion) and spironolactone (Sigma-Aldrich; Merck KGaA) was administered orally (100 $\mathrm{mg} / \mathrm{kg} /$ day $)$. The experimental rats were anesthetized with $2 \%$ pentobarbital solution at a dose of $3 \mathrm{ml} / \mathrm{kg}$, and UUO induction and aldosterone administration were conducted as follows: The rats were placed in the prone position and the retroperitoneal area was accessed through a skin incision. The left kidney was exposed, and the proximal ureter was ligated with 4-0 silk thread. At the time of UUO surgery, an Alzet 2002 osmotic mini-pump (Durect Corporation) was inserted subcutaneously between the shoulder blades; $0.75 \mu \mathrm{g} / \mathrm{h}$ aldosterone or vehicle was administered by subcutaneous infusion. All animals were sacrificed with $5 \%$ pentobarbital solution $(3 \mathrm{ml} / \mathrm{kg}$ ) 14 days after surgery and the obstructed kidneys were removed for analysis.

In vitro experiments. The RAW264.7 macrophage cell line was purchased from the American Type Culture Collection. RAW264.7 transduction was conducted using lentivirus vectors (pGLV3/H1/GFP+Puro Vector and LV5/EF-1 $\alpha$ F/GFP/Puro Vector) encoded with AIF-1 or an AIF-1 silencer, synthesized by Shanghai GenePharma Co. Ltd. Briefly, the cells were cultured in 24 -well plates $\left(5 \times 10^{4} /\right.$ well) in $0.5 \mathrm{ml}$ Dulbecco's modified Eagle's medium (DMEM; $10 \%$ FBS, Thermo Fisher Scientific, Inc.). Following incubation for $24 \mathrm{~h}$ at $37^{\circ} \mathrm{C}$, the cells were resuspended in $100 \mu 1$ fresh DMEM containing lentivirus vector or pShuttle vector $\left(5 \mu \mathrm{g} / \mathrm{ml}\right.$ per $1 \times 10^{8}$ cells $\left./ \mathrm{l}\right)$, and incubated for $48 \mathrm{~h}$. Following transduction, the stable transfectants were isolated using fluorescence and antibiotic selection $(2.5 \mu \mathrm{g} / \mathrm{ml}$ puromycin; Clontech Laboratories, Inc.). The expression of AIF-1 in the overexpression and knockdown cells was determined using western blotting and reverse transcription-quantitative (RT-q)PCR analysis. The pShuttle vector-transduced RAW264.7 cells (pShuttle), AIF-1-overexpressing cells and AIF-1/small interfering (s) iRNA cells $\left(5 \times 10^{4}\right.$; siRNA sequence: $5^{\prime}$-GGTGAAGTACAT GGAGTTTGA-3') were subsequently treated with aldosterone (10-6 M; Sigma-Aldrich, Merck KGaA); untreated RAW264.7 cells were used as a control. The cells were cultured in $75 \mathrm{~cm}^{2}$ bottles with $15 \mathrm{ml}$ DMEM (10\% FBS), harvested $72 \mathrm{~h}$ after transduction and subjected to mRNA and protein analyses.

Morphological analysis and immunohistochemistry. To evaluate the severity of tubulointerstitial inflammatory cell infiltration, kidney sections were processed and stained with hematoxylin and eosin (H\&E). Briefly, the renal tissue 
samples (fixed with 4\% paraformaldehyde solution or $24 \mathrm{~h}$ ) were embedded in paraffin and cut into $4-\mu$ m-thick slices. The paraffinized sections were stained with H\&E, analyzed by light microscopy and images were captured at x400 magnification. A total of $10 \mathrm{H} \& \mathrm{E}$-stained fields were randomly observed in each group, and the number of inflammatory cells in the average field was calculated by three experienced pathologists. Renal collagen deposition was evaluated using a Masson's trichrome staining kit (cat. no. BA-4079B; Baso Diagnostics, Inc.), which revealed collagen as blue-stained lesions in the kidney, and was semi-quantified using ImageJ 1.8.0 software (National Institutes of Health). Subsequently, 10 non-overlapping fields were scanned in each kidney section and the positively-stained areas were calculated as a percentage of the total area. The specific steps were as follows: All sections were stained with Wiegert-iron-hematoxylin (1:1) for $5 \mathrm{~min}$ at room temperature. Following washing in running water for $10 \mathrm{~min}$, the sections were treated with hydrochloride-ethanol solution (1\%) for $5 \mathrm{sec}$ at room temperature and rinsed under running tap water for a further $20 \mathrm{~min}$. The sections were stained in ponceau (1\%) staining solution for 5-10 min at room temperature (observed under an electron microscope at x200 magnification) and washed using phosphomolybdic acid solution (Baso Diagnostics, Inc.) for $5 \mathrm{~min}$ at room temperature. All sections were stained with aniline blue solution for $5 \mathrm{~min}$ at room temperature (observed under an electron microscope; magnification, $\mathrm{x} 400$ ), followed by washing in glacial acetic acid for $1 \mathrm{~min}$. Subsequent to dehydration with an ethanol series (95 and 100\%, 10 min each, twice) and xylene (5 min each, twice), all sections were mounted and the collagen tissues were stained blue. The sections were examined using light microscopy, and images of 10 non-repeating visual fields were randomly captured (magnification, x400). Immunohistochemistry was performed as described previously (3). For blocking the antigen, $5 \%$ bovine serum albumin was used for $20 \mathrm{~min}$ at room temperature. Then, the slides were incubated overnight at $4{ }^{\circ} \mathrm{C}$ with the following primary antibody: Polyclonal rabbit anti-rat AIF-1 (1:150; cat. no. ab153696; Abcam), and then an HRP-conjugated secondary antibody (1:100; SV0002, Boster Biological Technology, Ltd.) was used as the secondary antibody for $30 \mathrm{~min}$ at room temperature. Images were captured with a Nikon ECLIPSE 80i microscope (Nikon Corporation; magnification, $\mathrm{x} 400$ ), and positive staining was quantified using ImageJ software 1.8.0 software (National Institutes of Health); 10 non-overlapping fields were scanned in each kidney section and the areas of positive staining were calculated as a percentage of the total area.

RT-qPCR analysis. Total RNA was isolated from the kidney tissues and cells with the E.Z.N.A. Total RNA Kit II (Omega Bio-tek, Inc.) according to the manufacturer's protocol. cDNA was acquired by reverse transcription with the ImProm-II Reverse Transcriptase kit (Promega Corporation). qPCR was performed with FastStart Universal SYBR Green Master (ROX; Roche Diagnostics) using the $2^{-\Delta \Delta c q}$ method (21), the thermocycling conditions were as follows: $95^{\circ} \mathrm{C}$ for $10 \mathrm{~min}$ for activating FastStart Taq DNA Polymerase, $95^{\circ} \mathrm{C}$ for $15 \mathrm{sec}$, and $60^{\circ} \mathrm{C}$ for $1 \mathrm{~min}$ (40 cycles for amplification). The expression levels of the genes of interest were normalized to that of GAPDH. The following primers were used: AIF-1 forward,
5'-GTTCCCAAGACCCATCTAGAGCTG-3' and reverse, 5'-AGTTGGCTTCTGGTGTTCTTTGTTT-3'; PI3K forward, 5'-TTATTCTGGTTCTTGCGAAGTGAG-3' and reverse, 5'-TGCTGCGTGAAGTCCTGTAG-3'; AKT forward, 5'-GAG GAGGAGACGATGGACTTC-3' and reverse, 5'-GGCATA GTAGCGACCTGTGG-3'; mTOR forward, 5'-TTGTGTCCT GCTGGTCTGAAC-3' and reverse, 5'-GCTCTTTGTAGT GTAGTGCTTTGG-3'; GAPDH forward, 5'-AGGTCGGTG AACGGATTTG-3' and reverse, 5'-GGGGTCGTTGATGGC AACA-3'.

Western blotting. The preparation of protein samples from renal tissues and cells was performed as previously described (3). Briefly, protein was extracted in 1X SDS sample buffer following centrifugation at $12,000 \mathrm{x}$ g for $15 \mathrm{~min}$ at $4^{\circ} \mathrm{C}$. The protein concentration of each sample was measured using a BCA protein assay kit (cat. no. ab207002; Abcam). Equal quantities of protein $(20 \mu \mathrm{g})$ were separated using SDS-PAGE (8, 10 and $12 \%)$, transferred onto polyvinylidene difluoride membranes, and then blocked in Tris-buffered saline/Tween 20 containing $5 \%$ non-fat milk for $1 \mathrm{~h}$ at room temperature. The membranes were then incubated overnight at $4^{\circ} \mathrm{C}$ with the following primary antibodies: Rabbit anti-rat polyclonal AIF-1 (1:150; cat. no. ab153696; Abcam), rabbit anti-rat polyclonal Nrf2 antibody (1:200; cat. no. ab31163, Abcam), rabbit anti-rat polyclonal NOX2 antibody (1:300; cat. no. bs-3889R; Bioss Antibodies), rabbit anti-rat monoclonal p-PI3K p85 (1:200; cat. no. 4257; Cell Signaling Technology, Inc.), rabbit anti-rat monoclonal p-AKT (Ser473) (1:200; cat. no. 4060; Cell Signaling Technology, Inc.), rabbit anti-rat monoclonal p-mTOR (Ser2448) antibody (1:200; cat. no. \#5536; Cell Signaling Technology, Inc.) and anti- $\beta$-actin monoclonal antibody (1:2,000; cat. no. A00702; GenScript). Then the membranes were washed four times for 5 min with TBST and incubated with horseradish peroxidase conjugate-secondary antibodies (cat. no. ZB2301; 1:2,000 dilution; OriGene Technologies, Inc.) for $1 \mathrm{~h}$ at $37^{\circ} \mathrm{C}$. Imaging was performed with enhanced chemiluminescence (ECL; Beyotime Institute of Biotechnology) and the protein band densities were quantified by Gel-Pro-Analyzer 4.0 software (Media Cybernetics, Inc.). The results are expressed as an $n$-fold increase over the value of the control group.

Statistical analysis. SPSS 17.0 software (SPSS Inc.) was used to perform statistical analysis, and the results are presented as the mean \pm standard deviation. Differences between the means were assessed using one-way ANOVA and the differences between multiple groups were determined using Tukey's post hoc test. $\mathrm{P}<0.05$ was considered to indicate a statistically significant difference. All experiments were performed at least three times.

\section{Results}

Aldosterone promotes renal interstitial inflammatory cell infiltration and collagen deposition in normal rats. The profibrotic effects of aldosterone in normal rats were determined using H\&E and Masson's trichome staining. The results showed that aldosterone promoted renal interstitial inflammatory cell infiltration, tubular dilatation (Fig. 1A and B) and collagen 
A

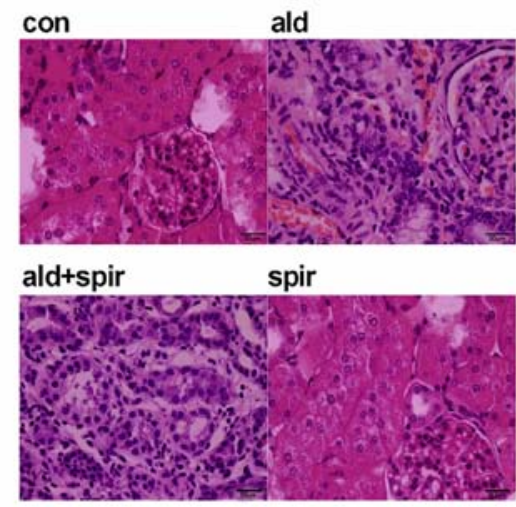

B

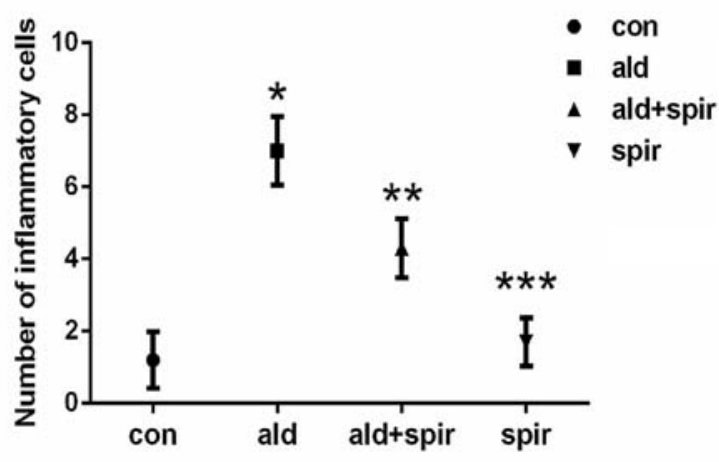

Figure 1. Hematoxylin and eosin staining of renal cortex sections (magnification, $\mathrm{x} 400$; scale bar=50 $\mu \mathrm{m}$ ). (A) Aldosterone ( $0.75 \mu \mathrm{g} / \mathrm{h}$ subcutaneous infusion) increased the degree of inflammatory cell infiltration in normal rats, which was subsequently reversed by spironolactone treatment (100 mg/kg/day). (B) Numbers of inflammatory cells in each group. ${ }^{*} \mathrm{P}<0.05$ vs. con group, ${ }^{* *} \mathrm{P}<0.05$ vs. ald group, ${ }^{* * * *} \mathrm{P}<0.05$ vs. ald + spir group. Data are presented as the mean \pm standard deviation $(n=10)$. Con, control; ald, aldosterone; spir, spironolactone.

A

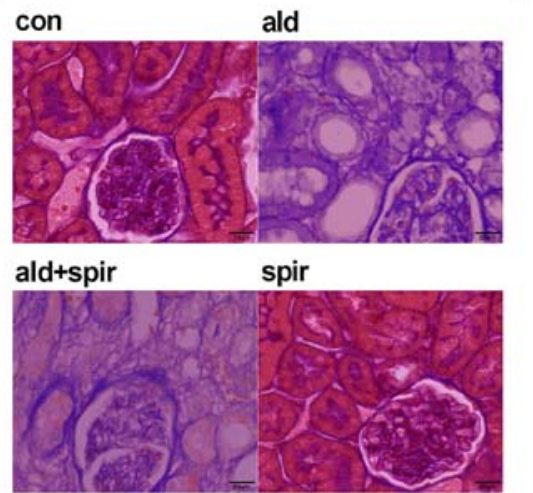

B

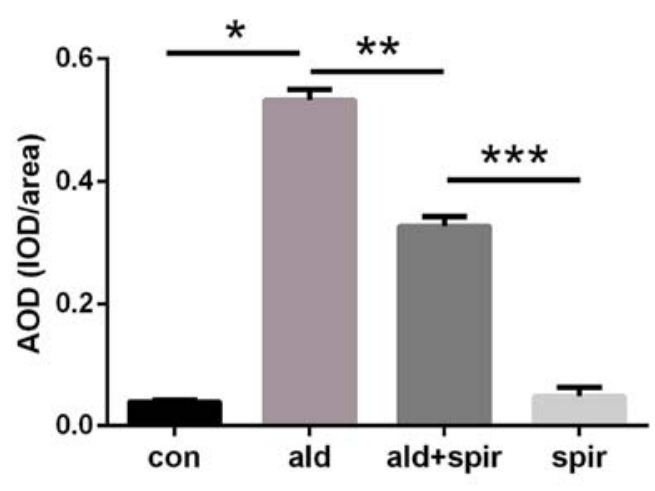

Figure 2. Masson's trichrome staining of renal cortex sections (magnification, $\mathrm{x} 400$; scale bar=20 $\mu \mathrm{m}$ ) and semi-quantitative analysis of collagen expression. (A) Interstitial collagen deposition (blue) was increased by aldosterone $(0.75 \mu \mathrm{g} / \mathrm{h}$ subcutaneous infusion) in the kidneys of normal rats and decreased in the aldosterone $(0.75 \mu \mathrm{g} / \mathrm{h}$ subcutaneous infusion $)+$ spironolactone $(100 \mathrm{mg} / \mathrm{kg} /$ day $)$ group. (B) Semi-quantified expression of collagen in each group. ${ }^{*} \mathrm{P}<0.05 \mathrm{vs}$. con group, ${ }^{* *} \mathrm{P}<0.05$ vs. ald group, ${ }^{* * *} \mathrm{P}<0.05$ vs. ald + spir group. Data are presented as the mean \pm standard deviation ( $=10$ ). Con, control; ald, aldosterone; spir, spironolactone; AOD, average optical density; IOD, integrated optical density.

deposition (Fig. 2A and B) in normal rats. Subsequent treatment with spironolactone reversed these pathological changes, indicating that aldosterone promoted renal interstitial fibrosis in normal rats.

Upregulation of AIF-1, PI3K, AKT, mTOR and NOX2, and downregulation of Nrf2 is induced by aldosterone in normal rats. The effects of aldosterone on the protein expression levels of AIF-1, PI3K, AKT, mTOR, NOX2 and Nrf2 were determined in normal rats. The results of western blotting revealed that aldosterone promoted the expression of AIF-1, PI3K, AKT, mTOR and NOX2, but inhibited the expression of $\mathrm{Nrf} 2$, and that spironolactone inhibited these effects (Fig. 3A-G).

Aldosterone promotes inflammatory cell infiltration and collagen deposition in UUO rats. To further investigate the role of aldosterone in renal interstitial fibrosis, a UUO model of fibrosis was established in rats and used to examine the effects of aldosterone on renal interstitial fibrosis. Histopathological changes to the ureteral obstructed kidney sections were evaluated using H\&E and Masson's trichrome staining. The H\&E staining results revealed considerable interstitial inflammatory cell infiltration in the aldosterone + UUO group compared with that in the UUO-only group, and that treatment with spironolactone decreased inflammatory cell infiltration (Fig. 4A and B). In line with the H\&E results, Masson's trichrome staining showed that, compared with UUO alone, aldosterone also increased interstitial collagen deposition at 14 days post-UUO, whereas the control group exhibited normal structure and reduced collagen expression; spironolactone treatment reversed the effects of aldosterone treatment (Fig. 5A and B).

Aldosterone increases the expression of AIF-1 in UUO rats. The expression of AIF-1 in the kidney tissues was detected by immunohistochemistry, and semi-quantitative analysis of AIF-1 was conducted using Image $\mathbf{J}$ software. The expression level of AIF-1 in the normal renal interstitium was low and was notably increased in the UUO group. Parallel to extracellular inflammatory cell infiltration and collagen deposition, aldosterone further increased the expression of AIF-1 
A

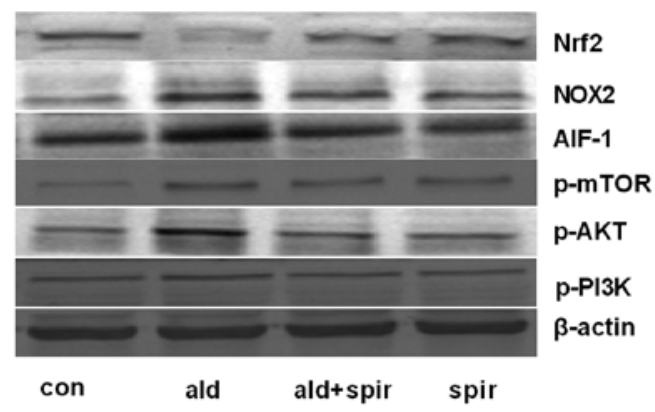

C

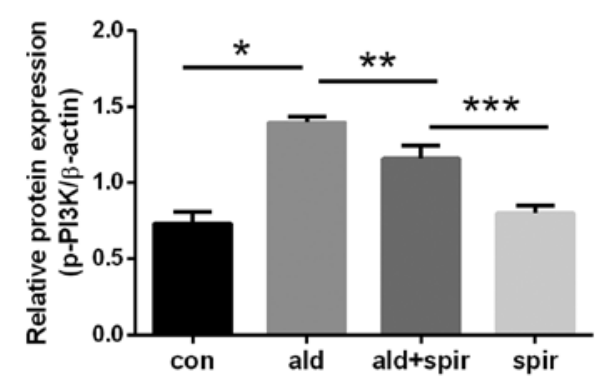

E

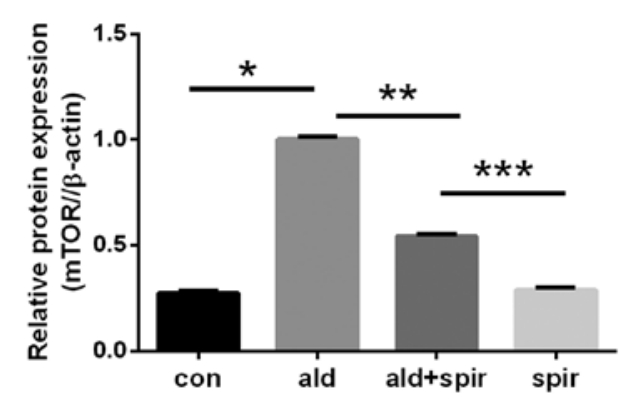

B

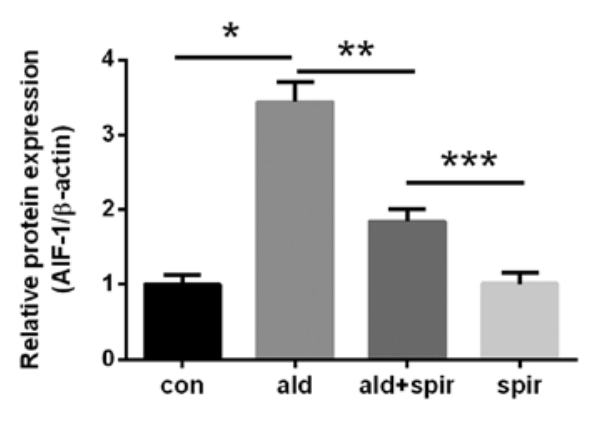

D

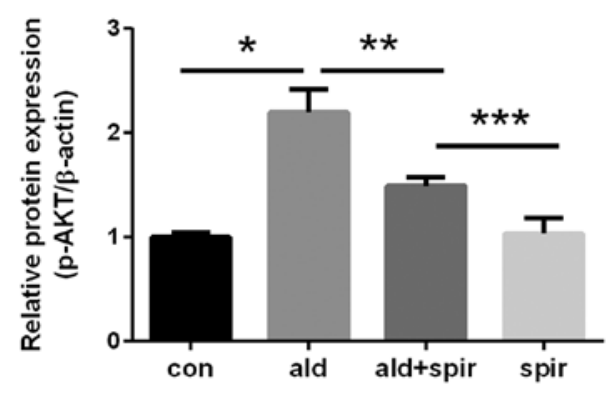

F

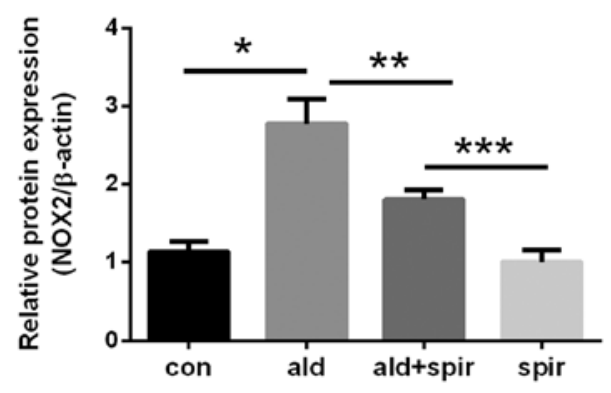

G

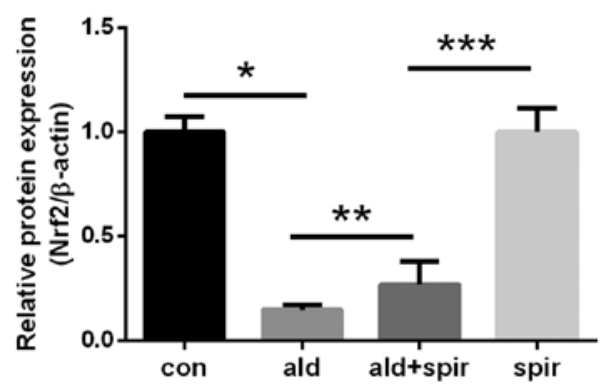

Figure 3. Effect of aldosterone on the protein expression levels of (A) AIF-1, p-PI3K, p-AKT, p-mTOR, NOX2 and Nrf2 in normal rats using western blotting. Aldosterone (0.75 $\mu \mathrm{g} / \mathrm{h}$ subcutaneous infusion) increased the expression of (B) AIF-1, (C) p-PI3K, (D) p-AKT, (E) p-mTOR and (F) NOX2 and decreased the expression of (G) Nrf2 in normal rats, which was attenuated by spironolactone $(100 \mathrm{mg} / \mathrm{kg} / \mathrm{day}) .{ }^{*} \mathrm{P}<0.05$ vs. con group, ${ }^{* *} \mathrm{P}<0.05$ vs. ald group ${ }^{* * * *} \mathrm{P}<0.05$ vs. ald + spir group. The data are presented as the mean \pm standard deviation $(n=3)$. AIF-1, allograft inflammatory factor-1; p-PI3K, phosphorylated phosphatidylinositol 3-kinase; p-AKT, phosphorylated AKT serine/threonine kinase; p-mTOR, phosphorylated mammalian target of rapamycin; NOX2, NADPH oxidase 2; $\mathrm{Nrf2}$, nuclear transcription factor erythroid-related factor 2; con, control; ald, aldosterone; spir, spironolactone.

compared with that in the UUO group, which was inhibited by spironolactone (Fig. 6A and B). The mRNA expression level of AIF-1 was also evaluated in the kidney, and the result was consistent with the increase induced by aldosterone in UUO rats observed in the quantitative immunohistochemical results (Fig. 7). 
A

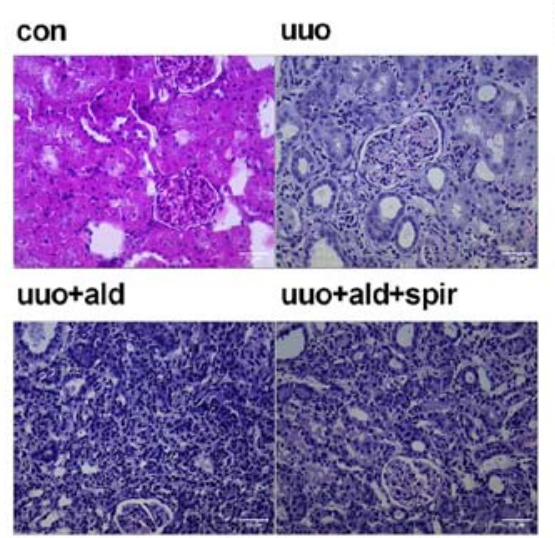

B

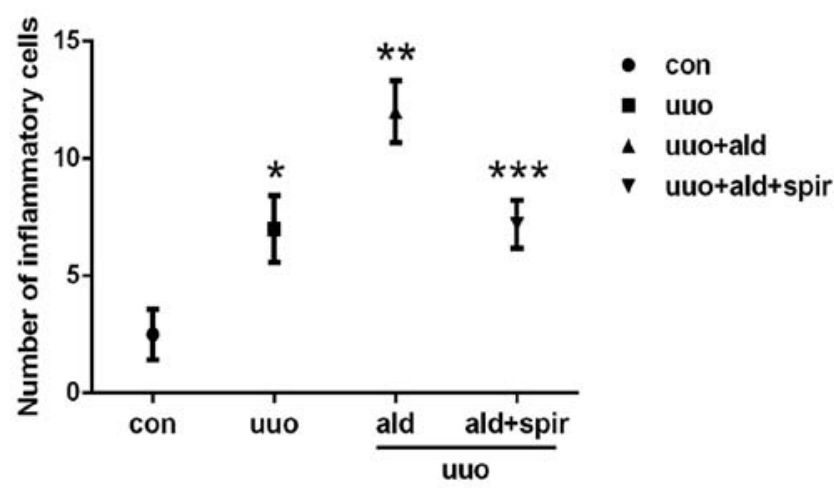

Figure 4. Hematoxylin and eosin staining of renal cortex sections (magnification, $\mathrm{x} 400$; scale bar=20 $\mu \mathrm{m}$ ). (A) Interstitial inflammatory cell infiltration in the UUO rats was increased in the obstructive kidney compared with that in the control group. Aldosterone $(0.75 \mu \mathrm{g} / \mathrm{h}$ subcutaneous infusion) further increased the degree of inflammatory cell infiltration, which was subsequently reversed by spironolactone treatment $(100 \mathrm{mg} / \mathrm{kg} / \mathrm{day})$. (B) Numbers of inflammatory cells in different group. ${ }^{*} \mathrm{P}<0.05$ vs. con group, ${ }^{* *} \mathrm{P}<0.05$ vs. UUO group, ${ }^{* * *} \mathrm{P}<0.05$ vs. UUO + ald group. Data are presented as the mean \pm standard deviation ( $\mathrm{n}=10$ ). Con, control; UUO, unilateral ureteric obstruction; ald, aldosterone; spir, spironolactone.

A

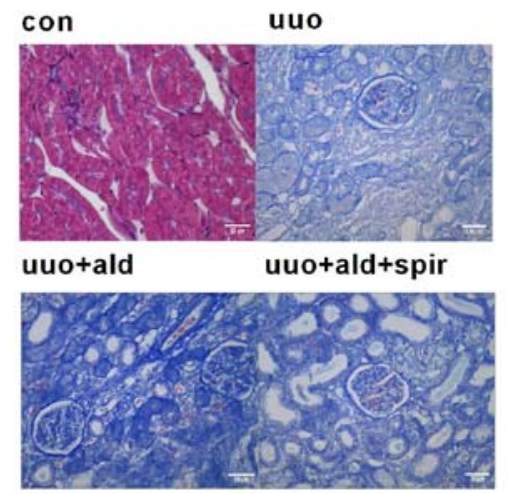

B

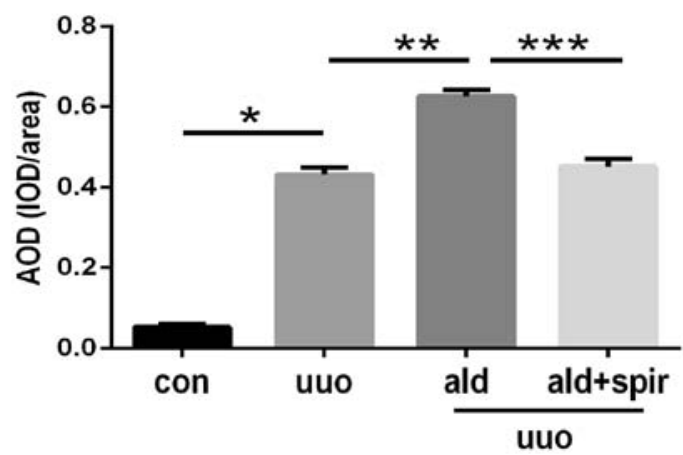

Figure 5. Masson's trichrome staining of renal cortex sections (magnification, $\mathrm{x} 400$; scale bar=20 $\mu \mathrm{m}$ ) and semi-quantitative analysis of collagen expression. (A) Interstitial collagen deposition (blue) was increased by aldosterone ( $0.75 \mu \mathrm{g} / \mathrm{h}$ subcutaneous infusion) in the obstructive kidney of the UUO rats and decreased in UUO rats treated with aldosterone $(0.75 \mu \mathrm{g} / \mathrm{h}$ subcutaneous infusion) and spironolactone (100 mg/kg/day) group. (B) Expression of collagen by semi-quantitative analysis. ${ }^{*} \mathrm{P}<0.05$ vs. con group, ${ }^{* *} \mathrm{P}<0.05$ vs. UUO group, ${ }^{* * *} \mathrm{P}<0.05$ vs. UUO + ald group. Data are presented as the mean \pm standard deviation $(n=10)$. Con, control; UUO, unilateral ureteric obstruction; ald, aldosterone; spir, spironolactone; AOD, average optical density; IOD, integrated optical density.

Aldosterone upregulates the expression of PI3K, AKT, mTOR, NOX2 and downregulates the expression of Nrf2 in the kidneys of UUO rats. In the ureteral obstructed kidney, the mRNA expression levels of PI3K, AKT and mTOR were significantly increased compared with those in the control group. Aldosterone administration further upregulated the mRNA expression levels of PI3K, AKT and mTOR in the UUO rats, whereas its effect was significantly inhibited by spironolactone (Fig. 8A-C). Concurrently, the protein expression levels of p-PI3K, p-AKT and p-mTOR in the kidney were increased by aldosterone compared with those in the UUO-only group, which was subsequently reversed by spironolactone (Fig. 9A-D).

In order to investigate the influence of aldosterone on oxidative stress in UUO rats, the protein expression levels of NOX 2 and Nrf2 were also determined by western blot analysis. The results revealed that aldosterone increased the expression level of NOX 2 and decreased that of Nrf2 in the UUO rats. Treatment with spironolactone attenuated the effects of aldosterone on the expression levels of NOX2 and Nrf2 (Fig. 9E and F).
AIF-1 mediates the activation of AKT, mTOR and aldosterone-induced oxidative stress in vitro. Based on the results of a previous study (3), the RAW264.7 macrophage cell line was selected to examine the potential effect of AIF-1 on the aldosterone-induced activation of the PI3K/AKT/mTOR pathway; these cells constitutively express low levels of AIF-1 and facilitate the positive selection of stable transfectants for AIF-1 gene overexpression and knockdown. The results showed that aldosterone increased the mRNA expression levels of PI3K, AKT and mTOR compared with those in the untreated cells. With the same concentration of aldosterone, the expression levels of AKT and mTOR were increased in the cells overexpressing AIF-1, compared with those in the control-transfected cells (pShuttle), although there was no obvious difference in the expression of PI3K. The mRNA expression levels of AKT and mTOR were decreased in the AIF-1/siRNA-transfected cells compared with those in the control cells stimulated with aldosterone; no difference in the mRNA expression level of PI3K was observed (Fig. 10A-C). The protein expression levels of 
A

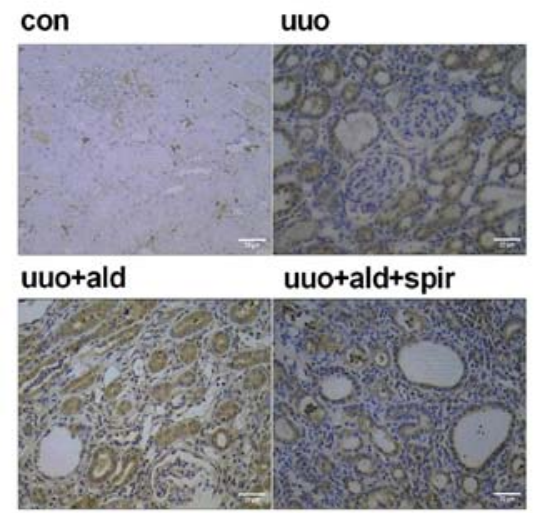

B

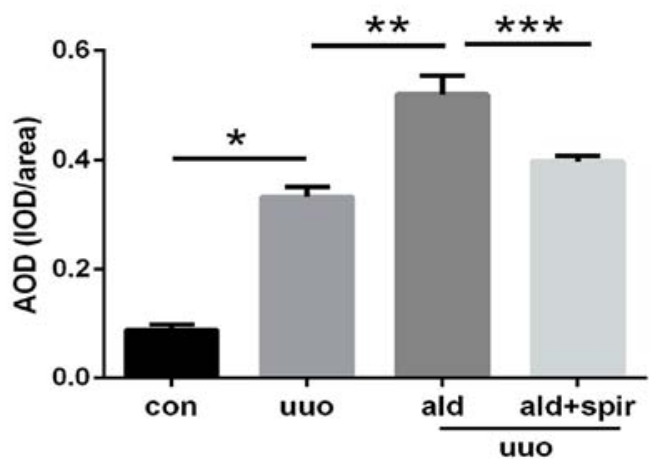

Figure 6. Expression of AIF-1 in renal sections by immunohistochemistry and semi-quantitative analysis of expression levels of AIF-1. Magnification, x400; scale bar $=20 \mu \mathrm{m}$. (A) Expression of AIF-1 was upregulated by aldosterone $(0.75 \mu \mathrm{g} / \mathrm{h}$ subcutaneous infusion $)$ in the UUO rat model of renal fibrosis, and inhibited by spironolactone treatment $(100 \mathrm{mg} / \mathrm{kg} / \mathrm{day})$. (B) Semi-quantitative analysis of expression levels of AIF-1. ${ }^{*} \mathrm{P}<0.05 \mathrm{vs}$. con group, ${ }^{* *} \mathrm{P}<0.05 \mathrm{vs}$. UUO group, ${ }^{* * *} \mathrm{P}<0.05$ vs. UUO + ald group. Data are presented as the mean \pm standard deviation $(\mathrm{n}=10)$. AIF-1, allograft inflammatory factor-1; con, control; UUO, unilateral ureteric obstruction; ald, aldosterone; spir, spironolactone; AOD, average optical density; IOD, integrated optical density.

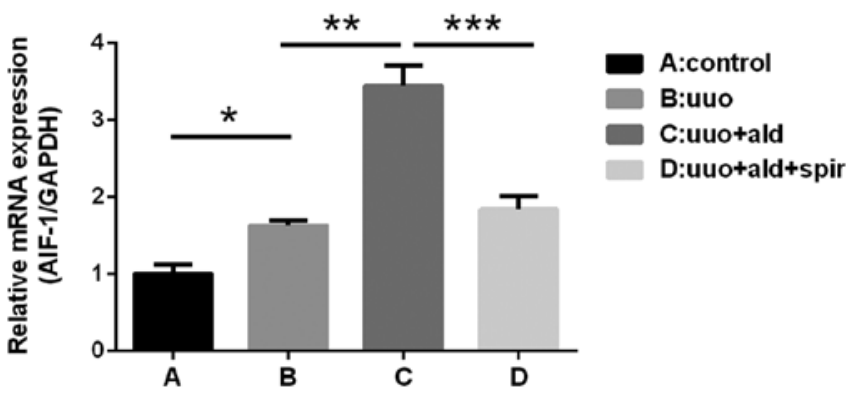

Figure 7. Reverse transcription-quantitative polymerase chain reaction analysis of the mRNA expression levels of AIF-1. ${ }^{*} \mathrm{P}<0.05$ vs. con group, ${ }^{* *} \mathrm{P}<0.05$ vs. UUO group, ${ }^{* * *} \mathrm{P}<0.05$ vs. UUO + ald group. Data are presented as the mean \pm standard deviation $(n=3)$. AIF-1, allograft inflammatory factor-1; UUO, unilateral ureteric obstruction; ald, aldosterone; spir, spironolactone.

p-PI3K, p-AKT and p-mTOR were also detected by western blotting, and the results showed that aldosterone increased the expression levels of p-PI3K, p-AKT and p-mTOR compared with those in the untreated cells. The expression levels of p-AKT and p-mTOR induced by aldosterone were increased in cells overexpressing AIF-1, compared with those in the control-transfected cells (pShuttle), although there was no significant difference in the expression of p-PI3K. The expression levels of p-AKT and p-mTOR were decreased in the AIF-1/siRNA-transfected cells compared with those in the control cells stimulated with aldosterone; no difference in the expression level of p-PI3K was observed (Fig. 11A-D).

To further investigate the role of AIF-1 in aldosterone-induced oxidative stress in RAW264.7 cells, the protein expression levels of NOX2 and Nrf2 were evaluated. It was demonstrated that aldosterone increased the expression levels of NOX 2 and Nrf 2 compared with those in the untreated cells. Additionally, the levels of NOX2 and Nrf2 were significantly upregulated in cells overexpressing AIF-1 compared with those in the control, pShuttle-transfected cells treated with aldosterone, whereas the expression levels were reduced in the AIF-1/siRNA-transfected cells compared with those in the control group cells (Fig. 11E and F).
A

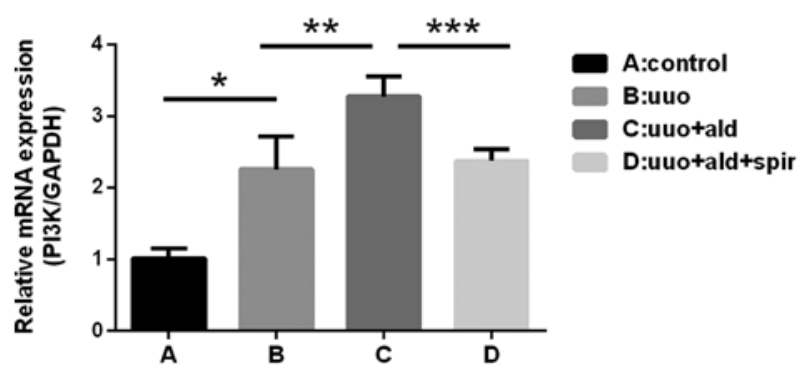

B

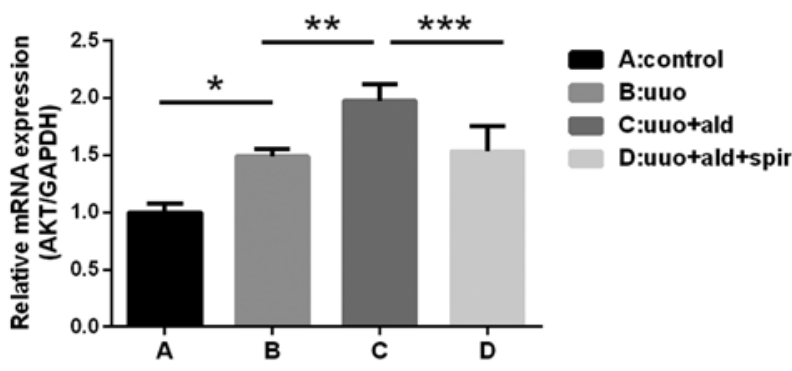

C

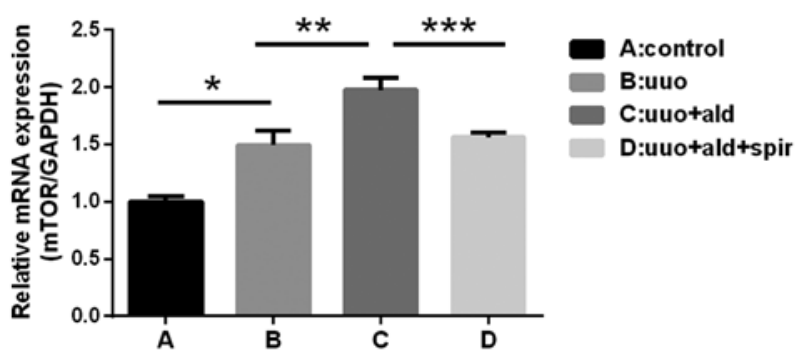

Figure 8. Effects of aldosterone on the mRNA expression of PI3K, AKT and mTOR. The mRNA expression levels of (A) PI3K, (B) AKT and (C) mTOR in UUO rats were upregulated following aldosterone $(0.75 \mu \mathrm{g} / \mathrm{h}$ subcutaneous infusion) treatment and reversed by spironolactone (100 mg/kg/day). ${ }^{*} \mathrm{P}<0.05$ vs. con group ${ }^{* *} \mathrm{P}<0.05$ vs. UUO group, ${ }^{* * *} \mathrm{P}<0.05$ vs. UUO + ald group. Data are presented as the mean \pm standard deviation $(n=3)$. PI3K, phosphatidylinositol 3-kinase; AKT, AKT serine/threonine kinase; mTOR; mammalian target of rapamycin; UUO, unilateral ureteric obstruction; ald, aldosterone; spir, spironolactone. 
A

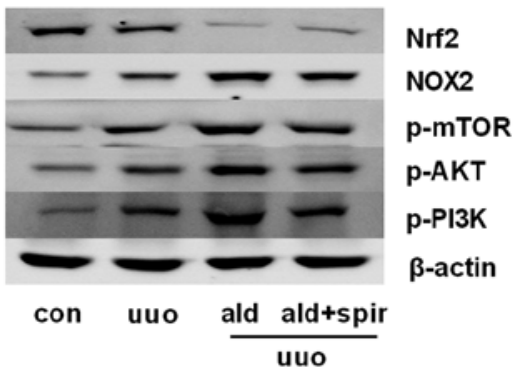

C
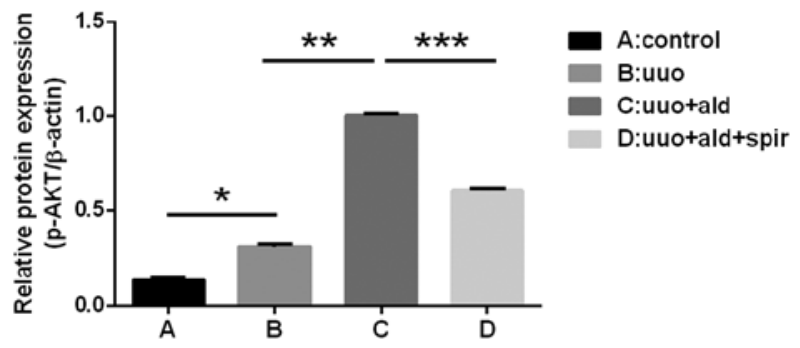

E

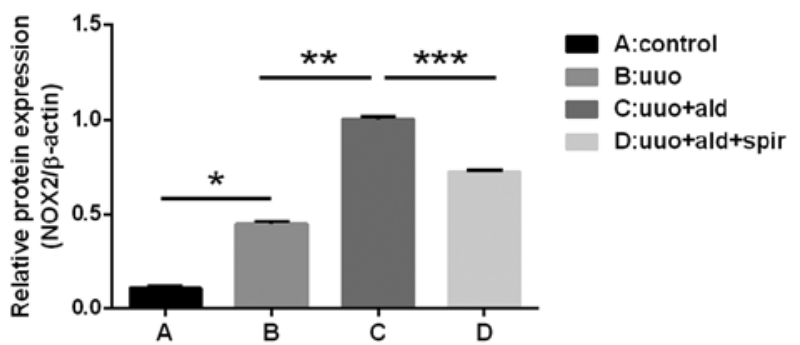

B

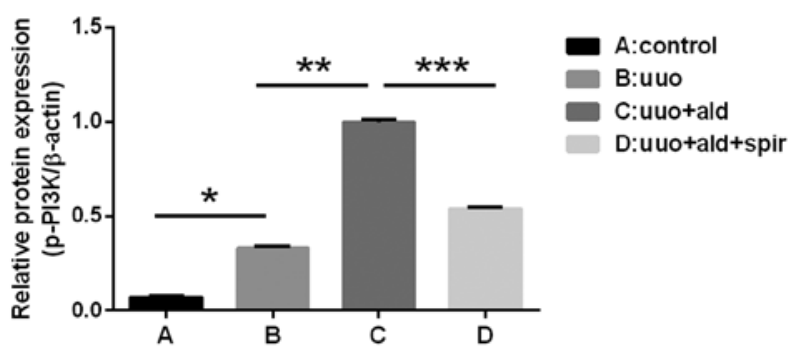

D

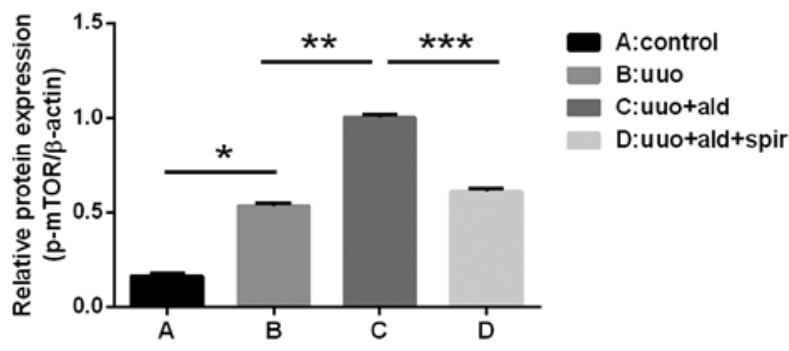

$\mathbf{F}$

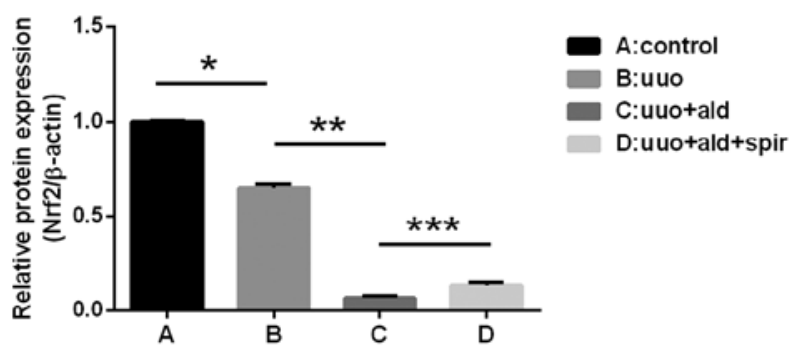

Figure 9. (A) Western blot analysis of the protein expression levels of p-PI3K, p-AKT, p-mTOR, NOX2 and Nrf2 in the rat kidney. Aldosterone $(0.75 \mu \mathrm{g} / \mathrm{h}$ subcutaneous infusion) upregulated the expression levels of (B) p-PI3K, (C) p-AKT, (D) p-mTOR and (E) NOX2 and downregulated the expression of (F) Nrf2, which was attenuated by spironolactone $(100 \mathrm{mg} / \mathrm{kg} / \mathrm{day}) .{ }^{*} \mathrm{P}<0.05$ vs. con group, ${ }^{* * *} \mathrm{P}<0.05$ vs. UUO group, ${ }^{* * *} \mathrm{P}<0.05$ vs. UUO + ald group. Data are presented as the mean \pm standard deviation $(\mathrm{n}=3)$. p-PI3K, phosphorylated phosphatidylinositol 3-kinase; p-AKT, phosphorylated AKT serine/threonine kinase; p-mTOR; phosphorylated mammalian target of rapamycin; UUO, unilateral ureteric obstruction; NOX2, NADPH oxidase 2; Nrf2, nuclear transcription factor erythroid-related factor 2; con, control; ald, aldosterone; spir, spironolactone.

\section{Discussion}

In the present study, aldosterone was found to promote inflammatory cell infiltration, collagen deposition and tubular dilatation in normal rat kidney tissues, and these pathological changes were alleviated following treatment with the mineralocorticoid receptor antagonist spironolactone. These results were consistent with those of another study (22) and highlighted the profibrotic effect of aldosterone.

It is well known that aldosterone is associated with the development of inflammatory renal fibrosis; the inflammatory factor AIF-1 is important in the activation and proliferation of macrophages, T lymphocytes, vascular smooth muscle cells and endothelial cells $(23,24)$. These cells are all involved in the response to injury in renal interstitial fibrosis (25). In anti-glomerular basement membrane nephritis, the expression level of AIF-1 was found to be upregulated in infiltrating cells (26). In patients with type 2 diabetes, the serum concentration of AIF-1 was positively correlated with urinary albumin excretion and inversely correlated with the estimated glomerular filtration rate (27). The results of the present study indicated that, accompanied with aldosterone-induced renal interstitial fibrosis, the expression level of AIF-1 was simultaneously increased by aldosterone in normal rats, which may indicate an important role of AIF-1 in kidney disease. However, few studies have been conducted to confirm the function of aldosterone-induced AIF-1 in the development of kidney fibrosis. Therefore, in the present study, the effect of aldosterone on AIF-1 was examined using the UUO model of renal interstitial fibrosis. The results demonstrated that aldosterone promoted inflammatory cell infiltration and collagen deposition in the UUO rats. In line with these pathological findings, the expression level of AIF-1 was upregulated by aldosterone in UUO rats compared with that in untreated 


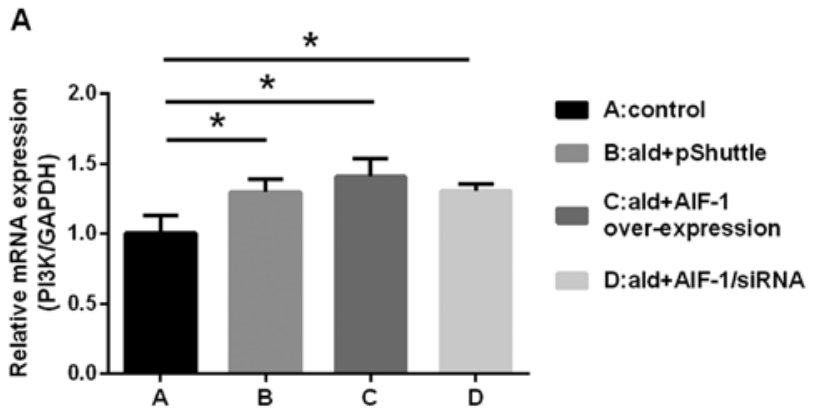

B

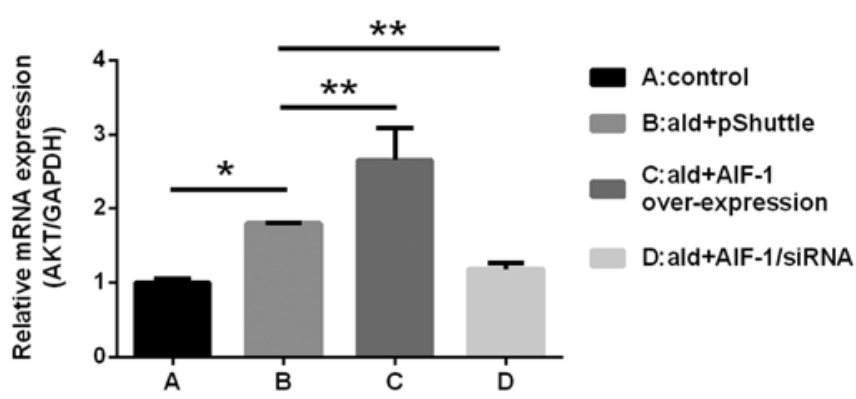

C

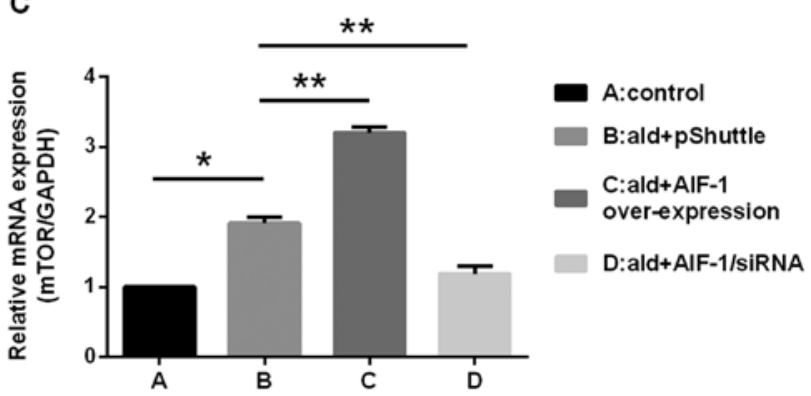

Figure 10. mRNA expression levels of (A) PI3K, (B) AKT and (C) mTOR in cells. Compared with the control (RAW264.7 cells only), mRNA expression levels of PI3K, AKT and mTOR were increased by aldosterone (10-6 M) in cells transfected with pShuttle. The expression levels of AKT and mTOR increased significantly in cells overexpressing AIF-1 and decreased in AIF-1/siRNA cells. " $\mathrm{P}<0.05$ vs. control, ${ }^{* *} \mathrm{P}<0.05$ vs. ald + pShuttle. Data are presented as the mean \pm standard deviation $(\mathrm{n}=3)$. ald, aldosterone; PI3K, phosphatidylinositol 3-kinase; AKT, AKT serine/threonine kinase; mTOR, mammalian target of rapamycin; AIF-1, allograft inflammatory factor-1; siRNA, small interfering RNA.

UUO rats. The pathological changes and elevated expression levels of AIF-1 were reversed by spironolactone, an inhibitor of the mineralocorticoid receptor; this indicated that aldosterone may induce kidney interstitial fibrosis through AIF-1 and its downstream signaling pathway, confirming the key role of AIF-1 in this pathogenic process.

Other studies have indicated an association between the expression of AIF-1 and signaling of the $\mathrm{PI} 3 \mathrm{~K} / \mathrm{AKT} / \mathrm{mTOR}$ pathway (14). PI3K promotes the conversion of phosphatidylinositol $(4,5)$-bisphosphate to phosphatidylinositol $(3,4,5)$-trisphosphate, which results in the activation of AKT (28). AKT activation is critically involved in epithelial-mesenchymal transition $(29,30)$, an important process in kidney fibrosis. AKT also regulates the expression of fibrotic proteins, including fibronectin and composition-like collagens $(31,32)$, and the excessive and persistent accumulation of fibronectin and composition-like collagens results in renal fibrosis. The activation of PI3K and AKT further induces the activation of mTOR, a central regulator of protein synthesis and cell growth in various cells and organs; the expression of phosphorylated PI3K, AKT and mTOR were reported to be increased in UUO rats (13), and collectively, these results indicate a potential role for the PI3K/AKT/mTOR signaling pathway in renal fibrosis. As supported by RT-qPCR results, aldosterone upregulated the mRNA expression levels of PI3K, AKT and mTOR in the UUO rats; concurrently, western blotting confirmed that aldosterone promoted the phosphorylation of PI3K, AKT and mTOR, and it was shown that these aldosterone-induced effects were reversed by spironolactone. This indicated a fibrotic role for the PI3K/AKT/mTOR signaling pathway in aldosterone-induced renal interstitial fibrosis.

There is evidence to suggest that inhibition of the expression of AIF-1 in macrophages suppresses the phosphorylation of AKT (6). A number of studies have shown that aldosterone promoted inflammatory cell infiltration in the kidney, including that of macrophages. The present study demonstrated considerably increased macrophage infiltration to the renal interstitium of UUO rats, indicating an important role for macrophages in renal interstitial fibrosis, in addition to the localization of AIF-1 in infiltrating macrophages (3). Therefore, the present study selected RAW264.7 macrophage cells, which constitutively express AIF-1, to investigate the effect of AIF-1 on the aldosterone-induced activation of AKT in vitro. This revealed that aldosterone increased the expression levels of AKT and mTOR in RAW264.7 cells transduced with the pShuttle vector and that the overexpression of AIF-1 further promoted the phosphorylation and increased mRNA expression levels of AKT and mTOR. By contrast, AIF-1 knockdown counteracted the effects of aldosterone on AKT and mTOR in RAW264.7 cells, indicating that AIF-1 serves an important role in the aldosterone-induced activation of AKT and mTOR in macrophages.

Aldosterone-induced renal injury is also associated with oxidative stress. NADPH oxidases, one of a number of sources of reactive oxygen species, are implicated in numerous pathophysiologic processes. Of the seven NADPH oxidase isoforms (Nox1-5, Duox1 and Duox2) identified, NOX2 is expressed at high levels in kidney tubular cells and endothelial cells and has been identified as a contributor to oxidative stress in kidney diseases (33). In diabetic NOX2-knockout mice, macrophage infiltration and the expression levels of chemotactic factor MCP-1 were significantly reduced in the kidney compared with observations in wild-type diabetic mice (34), indicating an association between inflammation and oxidative stress. In the present study, it was hypothesized that aldosterone exerted its effects on oxidative stress through the inflammatory factor AIF-1. The results showed that, in UUO rats, aldosterone upregulated the expression of ROS-generating enzyme NOX2, which was in line with the aldosterone-associated increase in the expression of NOX2 in interstitial cardiac fibrosis (35). In vitro, aldosterone increased the expression levels of NOX2 in pShuttle-transduced cells; this expression was further upregulated in cells overexpressing AIF-1, and the effect of aldosterone on the expression of NOX2 was attenuated in AIF-1-knockdown cells. These results verified the experimental hypothesis and may indicate a novel mechanism linking aldosterone to oxidative stress via AIF-1.

The aldosterone-associated upregulation of NOX2 in vivo was associated with the downregulation of $\mathrm{Nrf} 2$ in the UUO 
A

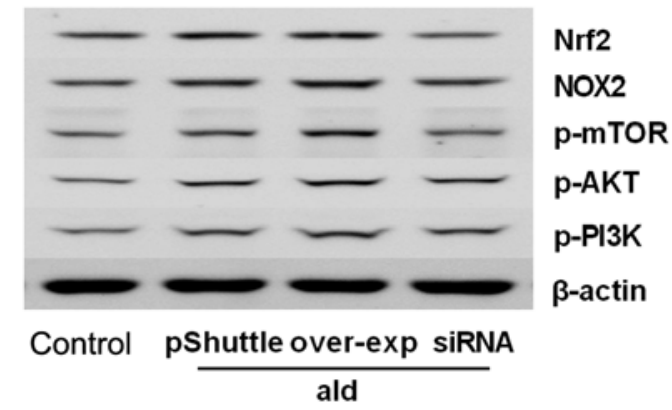

C

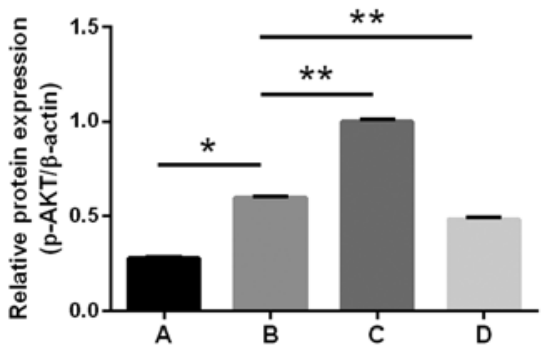

E

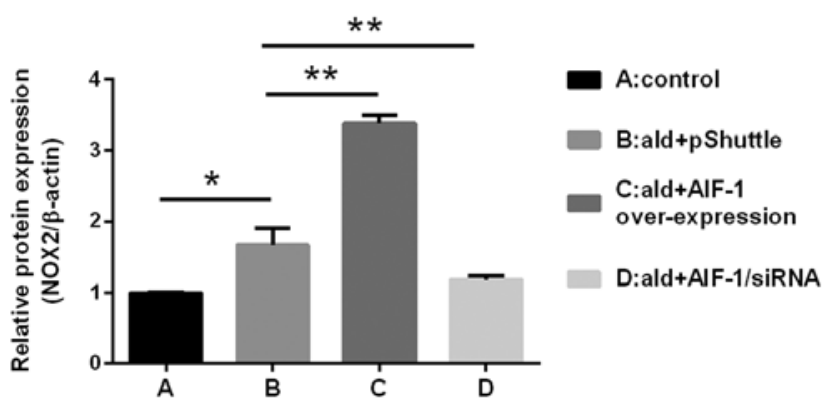

B

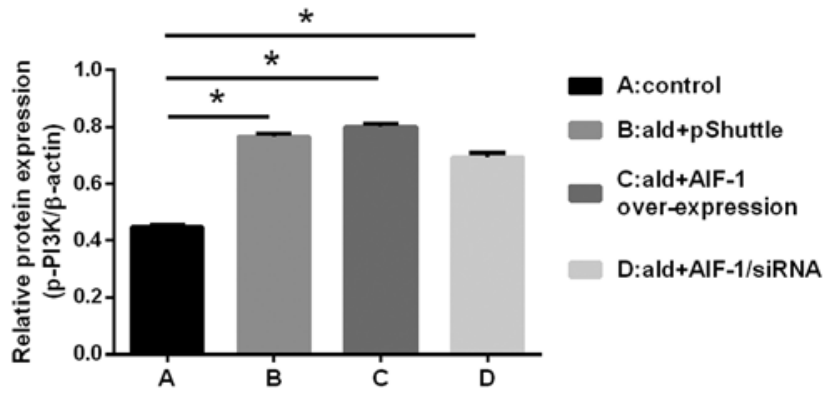

D

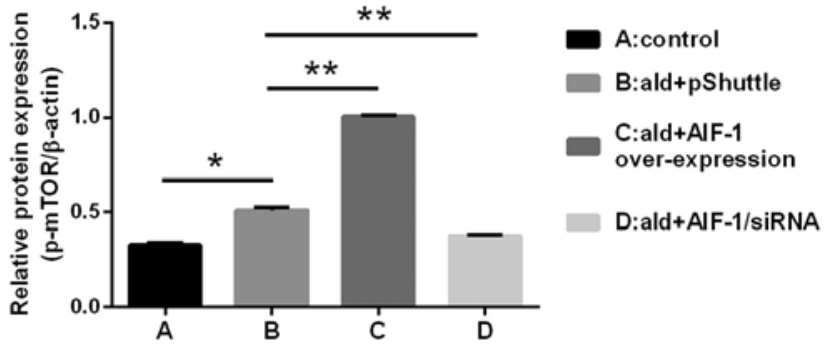

$\mathbf{F}$

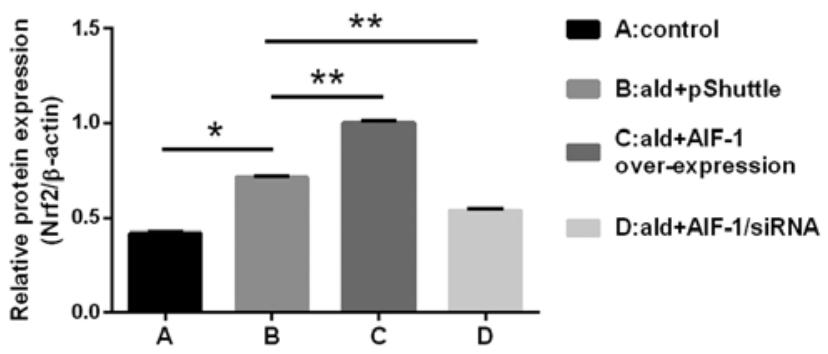

Figure 11. Effect of aldosterone on the protein expression levels of p-PI3K, p-AKT, p-mTOR, NOX2 and Nrf2 in RAW264.7 cells. Aldosterone (10-6 M) increased the expression levels of p-AKT, p-mTOR, NOX2 and Nrf2 via AIF-1 in RAW264.7 cells. (A) Western blot image of p-PI3K, p-AKT, p-mTOR, NOX2 and Nrf2 in different cells. Western blot analysis of (B) p-PI3K, (C) p-AKT, (D) p-mTOR, (E) NOX2 and (F) Nrf2. "P<0.05 vs. control, ${ }^{* *} \mathrm{P}<0.05$ vs. ald + pShuttle. Data are presented as the mean \pm standard deviation $(n=3)$. p-PI3K, phosphorylated phosphatidylinositol 3-kinase; p-AKT, phosphorylated AKT serine/threonine kinase; p-mTOR, phosphorylated mammalian target of rapamycin; NOX2, NADPH oxidase 2; Nrf2, nuclear transcription factor erythroid-related factor 2; AIF-1, allograft inflammatory factor-1; siRNA, small interfering RNA; over-exp, overexpression.

kidney. Nrf2 is an important antioxidative transcription factor, the activation of which ultimately results in transcriptional regulation of diverse phase II detoxification and antioxidant enzymes, including heme oxygenase 1 and NADPH quinone dehydrogenase 1 (36). These enzymes protect tissues and cells against oxidative stress. The overexpression of Nrf2 in transforming growth factor- $\beta$-treated rat mesangial cells and renal fibroblast cells decreased the expression of $\alpha$-smooth muscle actin, fibronectin and type 1 collagen (37). In the present study, the expression level of Nrf2 decreased significantly in aldosterone-treated UUO rats compared with that in the UUO-only group, 14 days after ureter ligation. Furthermore, the expression level of AIF-1 was upregulated, and these effects were reversed by spirolactone. These results indicated a possible correlation between AIF-1 and Nrf2 caused by aldosterone.
Notably, in RAW264.7 macrophage cells, $72 \mathrm{~h}$ of aldosterone treatment promoted the expression of Nrf2, which was further increased in cells overexpressing AIF-1 and decreased in AIF-1/siRNA RAW264.7 cells. These results indicated that AIF-1 may influence the expression of Nrf2. It has also been suggested that the upregulation of Nrf2 may be a transient, adaptive-protective response to inflammatory cytokines and AIF-1 in the early stages of aldosterone stimulation; this was supported by the results of Queisser et al (38) who also observed an increase in the expression level of Nrf2 following in vitro aldosterone treatment. However, in UUO rats, aldosterone may trigger a considerable inflammatory response and chemotactic effects; this early protective reaction may not be sufficient to counteract the profibrotic effects of UUO and aldosterone in vivo, ultimately leading to an imbalance in 
the complex interplay between injury and protective factors. This hypothesis was also supported by Queisser et al, who hypothesized that Nrf2 was activated rather than inhibited in aldosterone-induced liver fibrosis and, due to the limited awareness of liver disease at the time, the reduced expression level of Nrf2 was only observed in later disease stages (39).

In conclusion, the results of the present study indicated that aldosterone promoted renal interstitial fibrosis in UUO rats via AIF-1 and that AIF-1 serves an important role in AKT/mTOR activation and aldosterone-induced oxidative stress in macrophages. As a complicated dynamic process, further detailed investigations are required to elucidate the mechanism of aldosterone in renal fibrosis.

\section{Acknowledgements}

The authors would like to acknowledge the contributions of Professor Wei Wang and Dr Hui Wang (Molecular and Image Center laboratory, The Fourth Affiliated Hospital of Harbin Medical University, Harbin, China) for their technical assistance.

\section{Funding}

The present study was supported by the National Natural Science Foundation of China (grant. no. 81570638) and the Scientific Funding Project for the Returned Overseas of Education Department of Heilongjiang Province (grant. no. 1253HQ006).

\section{Availability of data and materials}

All data generated or analyzed during this study are included in this published article.

\section{Authors' contributions}

LH and XW were major contributors to the experimental design. XL established the animal models. SZ performed the protein analysis. YL and XY were involved in cell culture. XY was involved in writing the manuscript, and the analysis and interpretation of data. All authors read and approved the final manuscript.

\section{Ethics approval and consent to participate}

All experimental procedures adhered to the principles stated in the Guide for the Care and Use of Laboratory Animals (updated 2011; National Institutes of Health, Bethesda, MD, USA) and were approved by the Experimental Animal Usage and Welfare Ethics Committee of Harbin Medical University (Harbin, China).

\section{Patient consent for publication}

Not applicable.

\section{Competing interests}

The authors declare that they have no competing interests.

\section{References}

1. Kang YS, Ko GJ, Lee MH, Song HK, Han SY, Han KH, Kim HK, Han JY and Cha DR: Effect of eplerenone, enalapril and their combination treatment on diabetic nephropathy in type II diabetic rats. Nephrol Dial Transplant 24: 73-84, 2009.

2. Miana M, de Las Heras N, Rodriguez C, Sanz-Rosa D, Martin-Fernandez B, Mezzano S, Lahera V, Martinez-Gonzalez J and Cachofeiro V: Effect of eplerenone on hypertension-associated renal damage in rats: Potential role of peroxisome proliferator activated receptor gamma (PPAR- $\gamma$ ). J Physiol Pharmacol 62: 87-94, 2011.

3. Li Y, Wang X, Zhang L, Yuan X, Hao J, Ni J and Hao L: Upregulation of allograft inflammatory factor-1 expression and secretion by macrophages stimulated with aldosterone promotes renal fibroblasts to a profibrotic phenotype. Int J Mol Med 42: 861-872, 2018.

4. Deininger MH, Meyermann R and Schluesener HJ: The allograft inflammatory factor-1 family of proteins. FEBS Lett 514: $115-121,2002$.

5. Liu G, Ma H, Jiang L and Zhao Y: Allograft inflammatory factor-1 and its immune regulation. Autoimmunity 40: 95-102, 2007.

6. Chen X, Kelemen SE and Autieri MV: AIF-1 expression modulates proliferation of human vascular smooth muscle cells by autocrine expression of G-CSF. Arterioscler Thromb Vasc Biol 24: 1217-1222, 2004.

7. Watano K, Iwabuchi K, Fujii S, Ishimori N, Mitsuhashi S, Ato M, Kitabatake A and Onoé K: Allograft inflammatory factor-1 augments production of interleukin- $6,-10$ and -12 by a mouse macrophage line. Immunology 104: 307-316, 2001.

8. Del Galdo F, Artlett CM and Jimenez SA: The role of allograft inflammatory factor 1 in systemic sclerosis. Curr Opin Rheumatol 18: 588-593, 2006.

9. Liu Y, Mei C, Du R and Shen L: Protective effect of allograft inflammatory factor-1 on the apoptosis of fibroblast-like synoviocytes in patients with rheumatic arthritis induced by nitro oxide donor sodium nitroprusside. Scand J Rheumatol 42: 349-355, 2013.

10. Tian Y, Kelemen SE and Autieri MV: Inhibition of AIF-1 expression by constitutive siRNA expression reduces macrophage migration, proliferation, and signal transduction initiated by atherogenic stimuli. Am J Physiol Cell Physiol 290: C1083-C1091, 2006.

11. Lloberas N, Cruzado JM, Franquesa M, Herrero-Fresneda I, Torras J, Alperovich G, Rama I, Vidal A and Grinyó JM: Mammalian target of rapamycin pathway blockade slows progression of diabetic kidney disease in rats. J Am Soc Nephrol 17: 1395-1404, 2006.

12. Chen G, Dong Z, Liu H, Liu Y, Duan S, Liu Y, Liu F and Chen H: mTOR signaling regulates protective activity of transferred CD4+Foxp3+ $\mathrm{T}$ cells in repair of acute kidney injury. J Immunol 197: 3917-3926, 2016.

13. Ma SK, Joo SY, Kim CS, Choi JS, Bae EH, Lee J and Kim SW: Increased phosphorylation of PI3K/Akt/mTOR in the obstructed kidney of rats with unilateral ureteral obstruction. Chonnam Med J 49: 108-112, 2013.

14. Huang LL, Nikolic-Paterson DJ, Ma FY and Tesch GH: Aldosterone induces kidney fibroblast proliferation via activation of growth factor receptors and PI3K/MAPK signaling. Nephron, Exp Nephrol 120: E115-E122, 2012.

15. Toba H, Mitani T, Takahashi T, Imai N, Serizawa R, Wang J, Kobara $\mathrm{M}$ and Nakata T: Inhibition of the renal renin-angiotensin system and renoprotection by pitavastatin in type 1 diabetes. Clin Exp Pharmacol Physiol 37: 1064-1070, 2010.

16. Shan Q, Zhuang J,Zheng G, Zhang Z, Zhang Y,Lu J and Zheng Y: Troxerutin reduces kidney damage against BDE-47-induced apoptosis via inhibiting NOX2 activity and increasing Nrf2 activity. Oxid Med Cell Longev 2017: 6034692, 2017.

17. Karim AS, Reese SR, Wilson NA, Jacobson LM, Zhong W and Djamali A: Nox2 is a mediator of ischemia reperfusion injury. Am J Transplant 15: 2888-2899, 2015.

18. Fukuda M, Nakamura T, Kataoka K, Nako H, Tokutomi Y, Dong YF, Ogawa H and Kim-Mitsuyama S: Potentiation by candesartan of protective effects of pioglitazone against type 2 diabetic cardiovascular and renal complications in obese mice. J Hypertens 28: 340-352, 2010.

19. Aminzadeh MA, Nicholas SB, Norris KC and Vaziri ND: Role of impaired Nrf2 activation in the pathogenesis of oxidative stress and inflammation in chronic tubulo-interstitial nephropathy. Nephrol Dial Transplant 28: 2038-2045, 2013. 
20. Chang SY, Lo CS, Zhao XP, Liao MC, Chenier I, Bouley R, Ingelfinger JR, Chan JS and Zhang SL: Overexpression of angiotensinogen downregulates aquaporin 1 expression via modulation of Nrf2-HO-1 pathway in renal proximal tubular cells of transgenic mice. J Renin Angiotensin Aldosterone Syst 17: 1470320316668737, 2016.

21. Livak K and Schmittgen T: Analysis of relative gene expression data using real-time quantitative PCR and the 2(-Delta Delta C(T)) method. Methods 25: 402-408, 2001.

22. Brown NJ: Contribution of aldosterone to cardiovascular and renal inflammation and fibrosis. Nat Rev Nephrol 9: 459-469, 2013.

23. Autieri MV and Carbone CM: Overexpression of allograft inflammatory factor-1 promotes proliferation of vascular smooth muscle cells by cell cycle deregulation. Arterioscler Thromb Vasc Biol 21: 1421-1426, 2001.

24. Schluesener HJ, Seid K, Kretzschmar J and Meyermann R: Allograft-inflammatory factor-1 in rat experimental autoimmune encephalomyelitis, neuritis, and uveitis: Expression by activated macrophages and microglial cells. Glia 24: 244-251, 1998.

25. Tian Y, Jain S, Kelemen SE and Autieri MV: AIF-1 expression regulates endothelial cell activation, signal transduction, and vasculogenesis. Am J Physiol Cell Physiol 296: C256-C266, 2009.

26. Tsubata Y, Sakatsume M, Ogawa A, Alchi B, Kaneko Y, Kuroda T, Kawachi H, Narita I, Yamamoto T and Gejyo F: Expression of allograft inflammatory factor-1 in kidneys: A novel molecular component of podocyte. Kidney Int 70: 1948-1954, 2006.

27. Fukui M, Tanaka M, Asano M, Yamazaki M, Hasegawa G, Imai S, Fujinami A, Ohta M, Obayashi $\mathrm{H}$ and Nakamura $\mathrm{N}$ : Serum allograft inflammatory factor-1 is a novel marker for diabetic nephropathy. Diabetes Res Clin Pract 97: 146-150, 2012.

28. Ma Y, Vassetzky Y and Dokudovskaya S: mTORC1 pathway in DNA damage response. Biochim Biophys Acta Mol Cell Res 1865: 1293-1311, 2018.

29. Kattla JJ, Carew RM, Heljic M, Godson C and Brazil DP: Protein kinase B/Akt activity is involved in renal TGF-beta1-driven epithelial-mesenchymal transition in vitro and in vivo. Am J Physiol Renal Physiol 295: F215-F225, 2008

30. Meadows KN, Iyer S, Stevens MV, Wang D, Shechter S, Perruzzi C, Camenisch TD and Benjamin LE: Akt promotes endocardial-mesenchyme transition. J Angiogenes Res 1: 2, 2009.
31. Ghosh Choudhury G and Abboud HE: Tyrosine phosphorylation-dependent PI 3 kinase/Akt signal transduction regulates TGFbeta-induced fibronectin expression in mesangial cells. Cell Signal 16: 31-41, 2004.

32. Runyan CE, Schnaper HW and Poncelet AC: The phosphatidylinositol 3-kinase/Akt pathway enhances Smad3-stimulated mesangial cell collagen I expression in response to transforming growth factor-beta1. J Biol Chem 279: 2632-2639, 2004

33. Asaba K, Tojo A, Onozato ML, Goto A, Quinn MT, Fujita T and Wilcox CS: Effects of NADPH oxidase inhibitor in diabetic nephropathy. Kidney Int 67: 1890-1898, 2005.

34. You YH, Okada S, Ly S, Jandeleit-Dahm K, Barit D, Namikoshi T and Sharma K: Role of Nox2 in diabetic kidney disease. Am J Physiol Renal Physiol 304: F840-F848, 2013.

35. Johar S, Cave AC, Narayanapanicker A, Grieve DJ and Shah AM Aldosterone mediates angiotensin II-induced interstitial cardiac fibrosis via a Nox2-containing NADPH oxidase. FASEB J 20: 1546-1548, 2006

36. Numazawa S and Yoshida T: Nrf2-dependent gene expressions: A molecular toxicological aspect. J Toxicol Sci 29: 81-89, 2004.

37. Oh CJ, Kim JY, Choi YK, Kim HJ, Jeong JY, Bae KH, Park KG and Lee IK: Dimethylfumarate attenuates renal fibrosis via NF-E2-related factor 2-mediated inhibition of transforming growth factor- $\beta /$ Smad signaling. PLoS One 7: e45870, 2012.

38. Queisser N, Oteiza PI, Link S, Hey V, Stopper H and Schupp N: Aldosterone activates transcription factor Nrf2 in kidney cells both in vitro and in vivo. Antioxid Redox Signal 21: 2126-2142, 2014.

39. Queisser N, Happ K, Link S, Jahn D, Zimnol A, Geier A and Schupp N: Aldosterone induces fibrosis, oxidative stress and DNA damage in livers of male rats independent of blood pressure changes. Toxicol Appl Pharmacol 280: 399-407, 2014.

(i) $\mathrm{E}$ This work is licensed under a Creative Common EY NC ND Attribution-NonCommercial-NoDerivatives 4.0 International (CC BY-NC-ND 4.0) License. 